\title{
PESQUISA DE Campylobacter fetus e Tritrichomonas foetus EM REPRODUTORES BOVINOS DO ESTADO DE MATO GROSSO DO SUL
}

\author{
RESEARCH OF Campylobacter fetus E Tritrichomonas foetus IN BOVINE SIRES \\ OF MATO GROSSO DO SUL STATE
}

\author{
D. F. R. FRIAS ${ }^{1 *}$, L. O. C. SILVA ${ }^{2}$, C. O. SOARES ${ }^{2}$, V. F. SOUZA², D. I. KOZUSNY-ANDREANI ${ }^{1}$
}

\section{RESUMO}

A Campilobacteriose e a Trichomonose genital bovina são doenças infectocontagiosas, de transmissão sexual, que causam graves problemas reprodutivos. O objetivo do trabalho foi pesquisar a presença de Campylobacter fetus e Tritrichomonas foetus em touros utilizados na monta natural em rebanhos de alta genética. Foram selecionadas 10 fazendas do Estado de Mato Grosso do Sul e coletado esmegma dos reprodutores utilizados na última estação de monta por meio da introdução de swab estéril acoplado a uma pipeta de inseminação. Estes animais estavam em repouso sexual a 20 dias e foram realizadas três coletas, com intervalo de 15 dias. Para cultivo de Campylobacter fetus, o material foi colocado em meio de transporte de Lander, incubado por 72 horas a $37^{\circ} \mathrm{C}$ e filtrado. Alíquotas de $0,1 \mathrm{~mL}$ do material filtrado e não filtrado foram inoculadas em ágar BHI acrescido de $10 \%$ de sangue desfibrinado de equino com suplemento seletivo para Campylobacter e incubadas em jarras Gaspack, em microaerofilia, a $37^{\circ} \mathrm{C}$ por 72 horas. Em seguida, foi realizado esfregaço e coloração de Gram nas colônias suspeitas, as quais foram submetidas a testes bioquímicos. Para o cultivo de Tritrichomonas foetus, a amostra coletada foi colocada em tubo tipo Falcon contendo $10 \mathrm{ml}$ de meio Lactopep e incubado a $37^{\circ} \mathrm{C}$, por 10 dias, com observação diária em microscópio de contraste de fase, e em casos suspeitos foi realizada a coloração de Giemsa.

Em todas as amostras analisadas, nenhuma apresentou crescimento de Tritrichomonas foetus e/ou Campylobacter fetus. Notou-se que em rebanhos bovinos produtores de alta genética, as estratégias indicadas para o controle desses patógenos acontecem de maneira natural, assim, é comum sua ausência. Já em rebanhos que adquirem animais para reprodução, além da manutenção destas medidas estratégicas, também seria interessante a utilização da vacinação nestes animais, pois a mesma vem demonstrando alta eficácia.

PALAVRAS-CHAVE: BOVINOS. CAMPILOBACTERIOSE. DOENÇAS REPRODUTIVAS. TRICHOMONOSE.

AGRADECIMENTOS: FUNDECT/MS, CNPq, Embrapa Gado de Corte, Universidade Camilo Castelo Branco - UNICASTELO/Fernandópolis, fazendas parceiras.

ÁREA TEMÁTICA: Doenças Infecciosas. 